\title{
OA12.02. CAM utilization among underserved patients in a safety-net hospital
}

\author{
P Gardiner \\ From International Research Congress on Integrative Medicine and Health 2012 \\ Portland, Oregon, USA. 15-18 May 2012
}

\section{Purpose}

Little is known about the relationship between complementary and alternative medicine (CAM) usage and factors associated with underserved patients, such as health literacy, homelessness, alcohol and drug use, and high depression status.

\section{Methods}

This is a secondary database analysis of the Project RED dataset $(\mathrm{N}=623)$ identifying the sociodemographic characteristics as well as underserved patient factors associated with CAM use. We used descriptive statistics, bivariate, and multivariate logistic regression. We used multivariate logistic regression models for each outcome (any CAM use, CAM provider delivered therapies, and relaxation practices), testing the association with independent variables associated with underserved patients.

\section{Results}

In this underserved population $(\mathrm{N}=623), \mathrm{CAM}$ use was reported by $51 \%$ of the non-Hispanic blacks, $40 \%$ of Hispanics, and $53 \%$ of the non-Hispanic whites. Twenty-seven percent used any relaxation techniques, and $28 \%$ used any practitioner delivered therapy. In this sample, individuals with a higher health literacy $\left(>9^{\text {th }}\right.$ grade) were approximately three times [odds ratio 2.97 , confidence interval $(1.82,4.86)]$ more likely to use relaxation techniques compared to those with a lower health literacy. Those who used illegal drugs were more likely to use any CAM [odds ratio $=1.81(1.14-2.88)$ ] and relaxation techniques [odds ratio $=2.61(1.56$ 4.38)]. Those with mild depression were three times [odds ratio $=2.86(1.19,6.83)]$ more likely to use only relaxation techniques compared to those with no depression.

\footnotetext{
Boston Medical Center, Boston, USA

() 2012 Gardiner; licensee BioMed Central Ltd. This is an Open Access article distributed under the terms of the Creative Commons Attribution License (http://creativecommons.org/licenses/by/2.0), which permits unrestricted use, distribution, and reproduction in any medium, provided the original work is properly cited.

\section{Conclusion}

It is important for providers to recognize that underserved patients utilized CAM and more research is needed to understand the patterns of CAM use in relation to access to care.

Published: 12 June 2012

doi:10.1186/1472-6882-12-S1-O46

Cite this article as: Gardiner: OA12.02. CAM utilization among

underserved patients in a safety-net hospital. BMC Complementary and Alternative Medicine 2012 12(Suppl 1):O46. and take full advantage of:

- Convenient online submission

- Thorough peer review

- No space constraints or color figure charges

- Immediate publication on acceptance

- Inclusion in PubMed, CAS, Scopus and Google Scholar

- Research which is freely available for redistribution 